\title{
Research Paper: Designing and Determining Validity and Reliability of the Questionnaire for Parents Satisfaction With the Services Provided for Children With Hearing Loss
}

\author{
Samira Khalifeh Loo ${ }^{1}$, ${ }^{*}$ Hosein Mobaraki ${ }^{1}$, Mohammad Kamali ${ }^{1}$, Zahra Jafari ${ }^{1}$ \\ 1. Department of Rehabilitation Management, School of Rehabilitation Sciences, Iran University of Medical Sciences, Tehran, Iran.
}

Chation: Khalifeh Loo S, Mobaraki H, Kamali M, Jafari Z. [Designing and Determining Validity and Reliability of the Questionnaire for Parents' Satisfaction With the Services Provided for Children With Hearing Loss (Persian)]. Journal of Rehabilitation. 2016; 17(3): 244-251. http://dx.doi.org/10.21859/jrehab-1703244

doi : http://dx.doi.org/10.21859/jrehab-1703244

Received: 22 Dec. 2015 Accepted: 06 Apr. 2016

Keywords: Satisfaction, Hearing loss, Hearing services in the area, Parents

\begin{abstract}
Objective Parents' satisfaction with the services for children with hearing loss is one of the most important indicators in evaluating the effectiveness of therapeutic and rehabilitation programs for such children. Accordingly, in the present study, the validity and reliability of the questionnaire for parents' satisfaction with the services provided for hearing-impaired children under the age of 6 years are examined .

Materials \& Methods In this descriptive and analytical research work, the questionnaire under study was completed by 60 randomly selected parents in Tehran who had used the training and rehabilitation services of these centers for at least one year. Fifteen of these parents were re-tested to assess reliability. The questionnaire was composed of 5 subtests of satisfaction of structural facilities (7 questions), satisfaction of sanitation conditions (10 questions), satisfaction of services and performance of the center (18 questions), satisfaction of the communication and the behavior of the staffs (12 questions), and satisfaction of fees against the services (3 questions). Internal consistency in level item and scale, items correlation with the total scale, test-retest repeatability, face validity, and content validity were also evaluated. Finally, the available data were analyzed by using SPSS (version 17) software. The other statistical methods included the Cronbach's alpha coefficients, Spearman correlation, and the tests of Kolmogorov-Smirnov Friedman, Kruskal-Wallis, and U-Mann Whitney. Results In relation to psychometric properties, 0.79 validity of the questionnaire and $90 \%$ reliability of internal consistency were obtained. Adequate correlations with the total scale were found for each item. In addition, the test-retest reliability was $75 \%$. Most of the parents were found to be satisfied or pretty satisfied with most of the service areas of the centers, including overall satisfaction (69.5\%), structural and environmental facilities (80.66\%), sanitation conditions (75\%), services and the performance of the center (91.66\%), communication and stuff attitude (91.66\%), and cost (55.5\%). Among the items of the questionnaire, the greatest satisfaction was related to communication and staff attitude $(S D=0.31, M=4.72)$, and the lowest satisfaction was with the fees of the service center $(S D=0.62, M=3.27)$. The result of Spearman correlation between specific dimensions and overall satisfaction showed significantly positive correlation $(P<0.01)$, which confirmed the validity of the questionnaire's structure. The satisfaction of services received, age, education, number of family members with disabilities, time to clinic and hearing parents were not significantly correlated. Conclusion The results of this study suggest that the questionnaire has good validity and reliability. In addition, it seems that the parents' satisfaction is high with respect to the services of the centers.
\end{abstract}

\section{* Corresponding Author:}

Hossein Mobaraki, PhD

Address: Department of Rehabilitation Management, School of Rehabilitation Sciences, Iran University of Medical Sciences, Shah Nazari St., Mohseni Sq., Mirdamad Blvd., Tehran, Iran.

Tel: +98 (21) 22228051

E-Mail: hmobaraki43@yahoo.com 


\title{
طراحى و تعيين روايى و يايايى يرسشنامه رضايت والدين ازخدمات ارائدشده به كودكان كمشنوا
}

\author{
سميرا خليفهلو'، "حسين مباركى'، محمد كمالى'، زهرا جعفرى'
}

1- كروه مديريث توانبخشى، دانشكده علوم توانبخشى، انشكاه علوم يزشكى ايران، تهران، ايران.

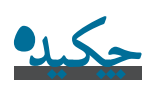

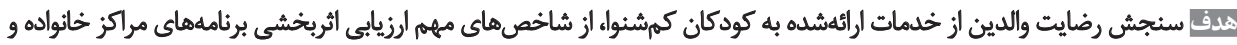

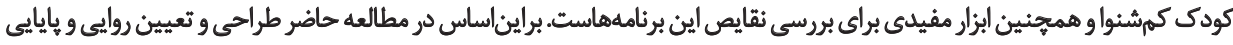

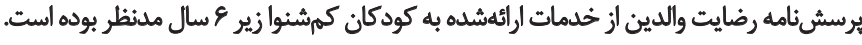

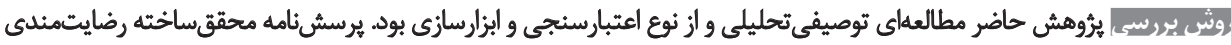

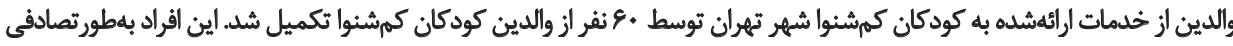

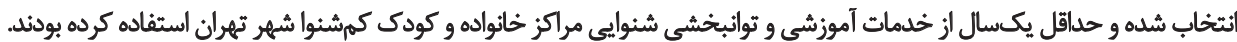

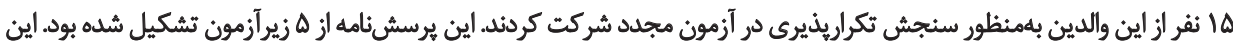

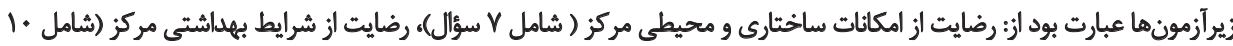

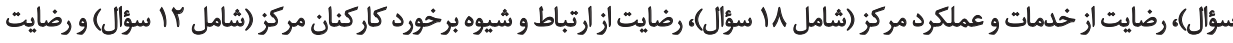

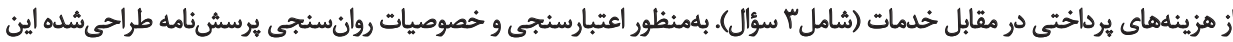

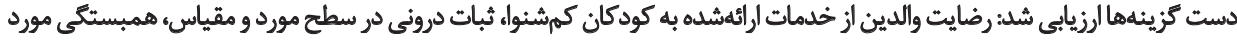

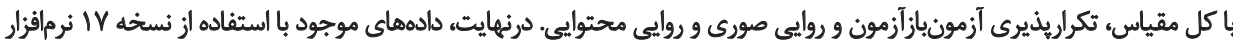

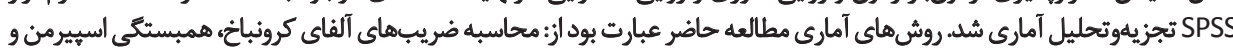

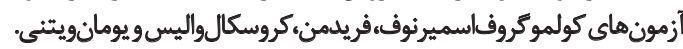

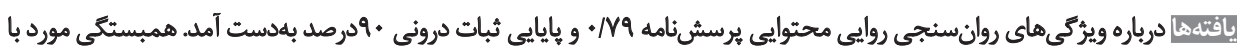

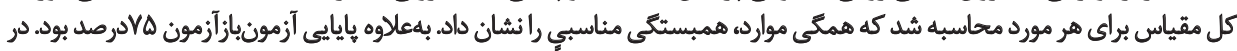

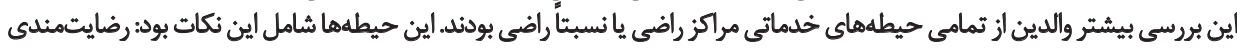

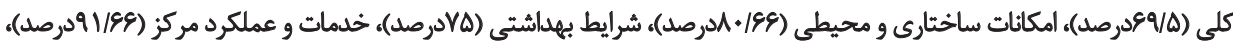

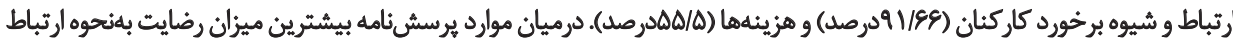

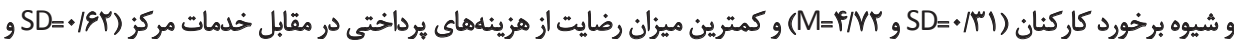

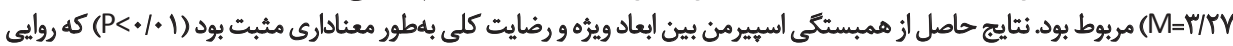

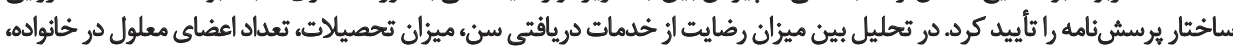

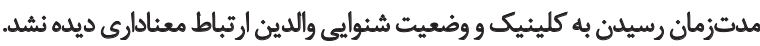

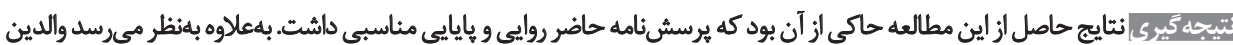

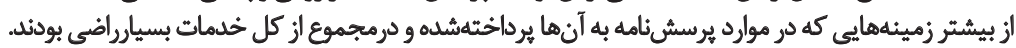

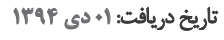

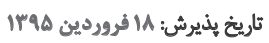

كليدوأوها:

رضايت، كمرشنوايبي، خدمات در حوزه شنوايتي، والدين 
از مطالعات خارجى مى توان به بئوهش يانك' و همكارانش

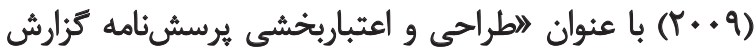

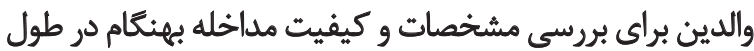

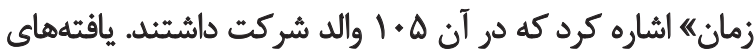

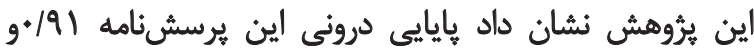

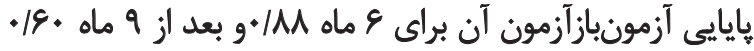

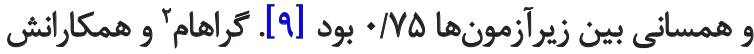

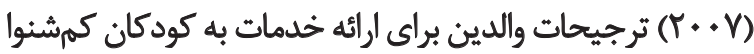

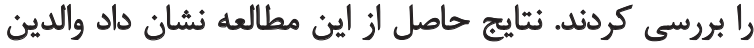

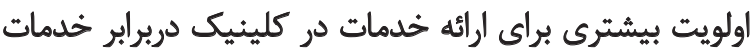

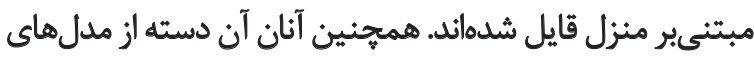

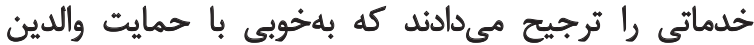
هماهنگ شده باشد إهـ].

هرجند ابزارهاى عمومى سنجش ميزان رضايت از خدمات

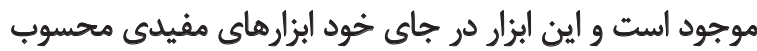

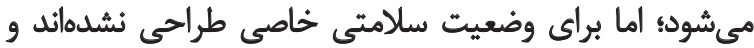

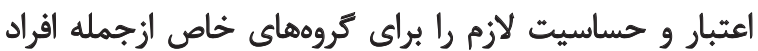

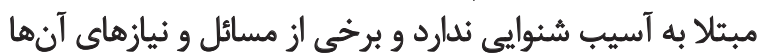

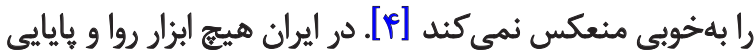

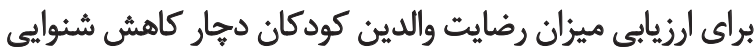

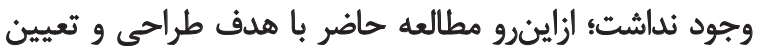

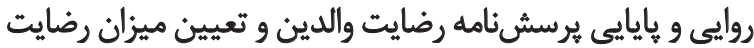

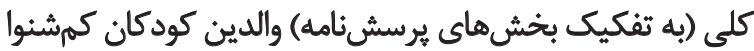

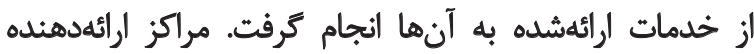

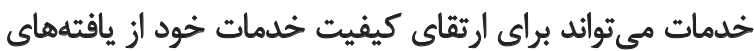

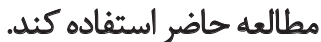

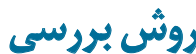

مطالعه حاضر مطالعهاى توصيفى تحليلى بود. اين مطالعه شامل

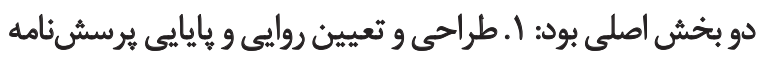

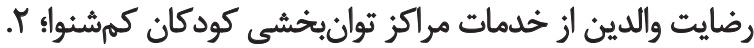

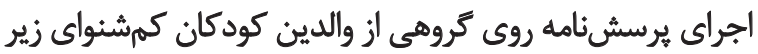

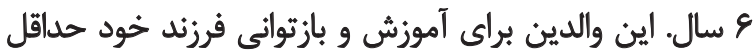

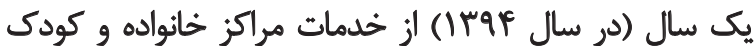

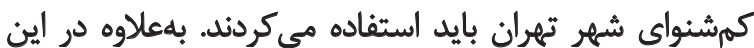
مطالعه نمونه ها بهطور تصادفى انتخاب شدند.

الكوى تهيه برسشرنامه حاضر مطالعات كَّشته و نظر

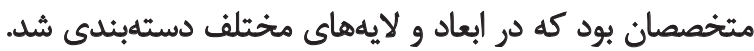

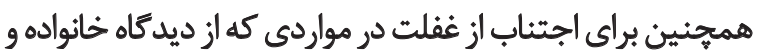

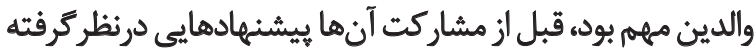

مقدمه

بشر از آغاز حيات خود با اتفاقات متعددى دركير بوده كه اين

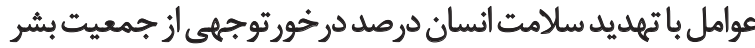

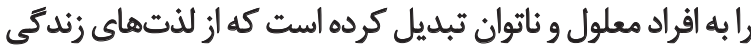

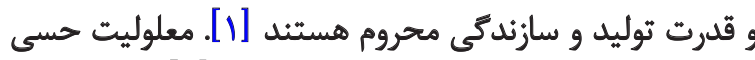

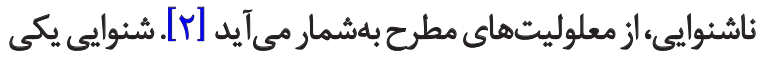

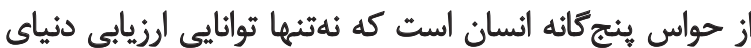

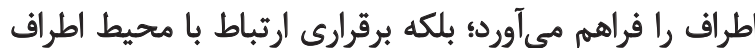

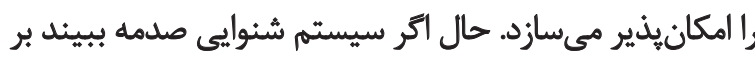

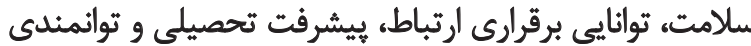

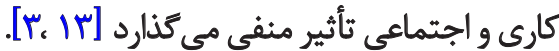

طى سالهاي اخير درزمينه شناسايى افت شنوائي كودكان

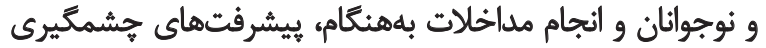

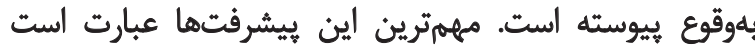

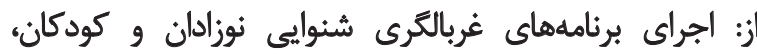

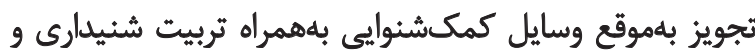

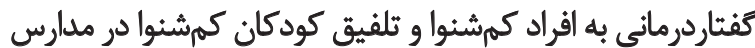

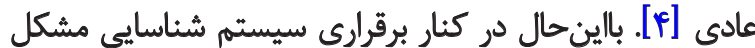

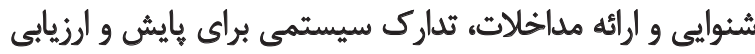

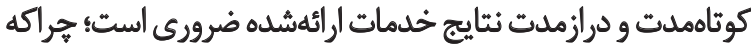

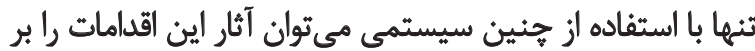

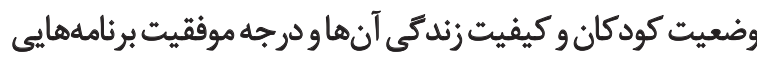

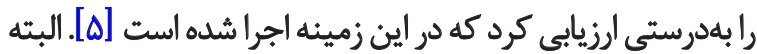

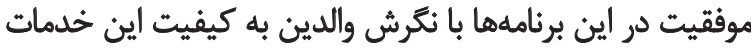

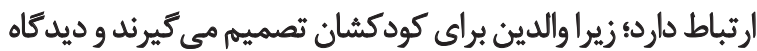
ايشان در موفقيت برنامه حائز اهميت است كودكان تصعالـ

در ايران درزمينه ميزان رضايت دريافت كنئدكان خدمات

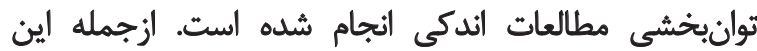

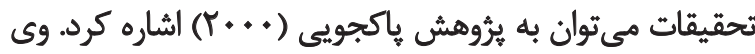

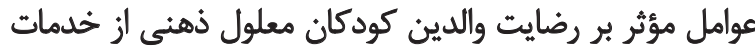

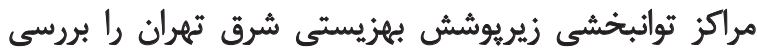

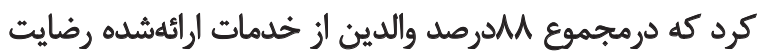

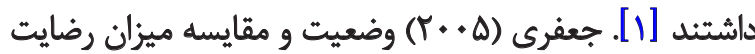

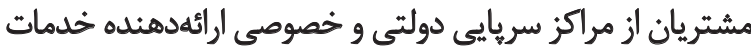

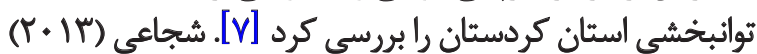

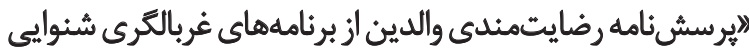

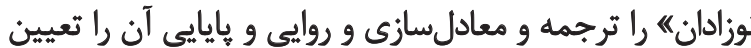

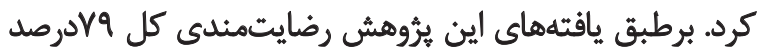

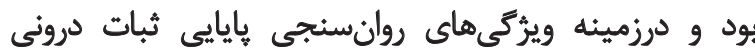

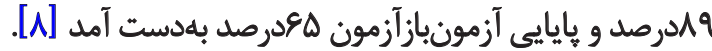




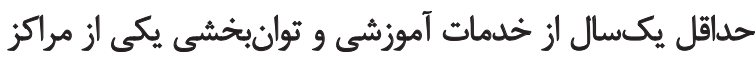

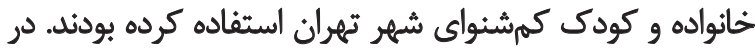

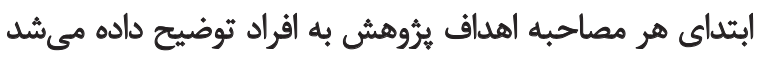

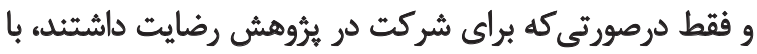

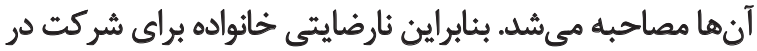

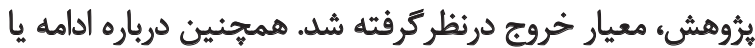

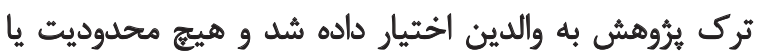

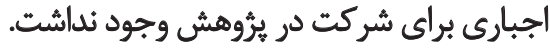

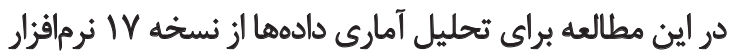
SPSS

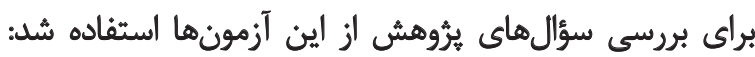

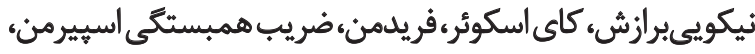

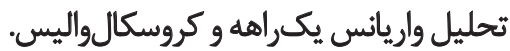

\section{يافتلها}

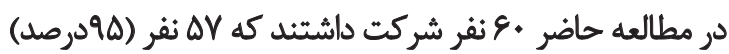

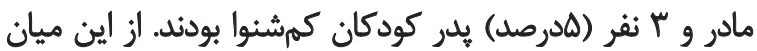

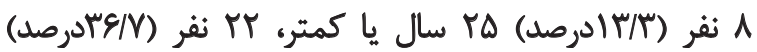

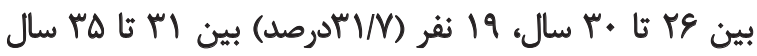

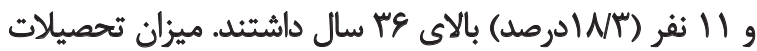

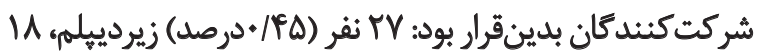

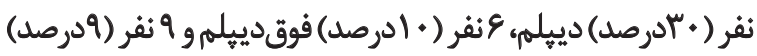

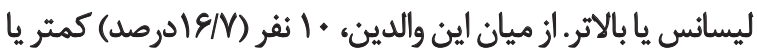

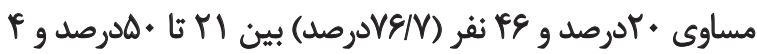

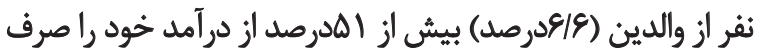

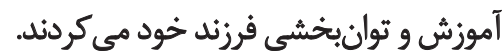

در اين يُروهش ينج متغير امكانات ساختارى و محيطى،

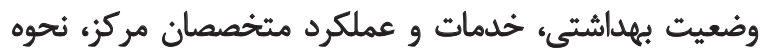

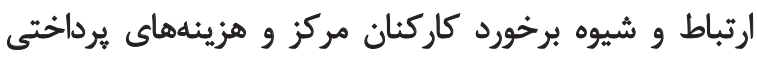

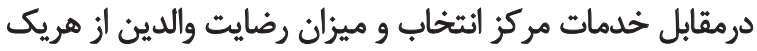

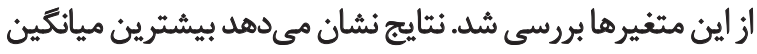

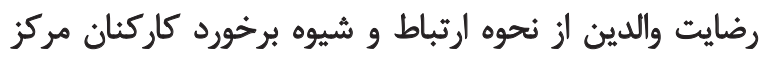

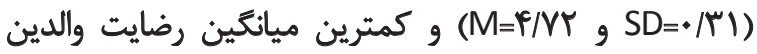

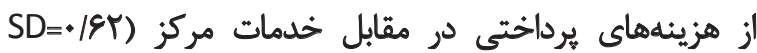

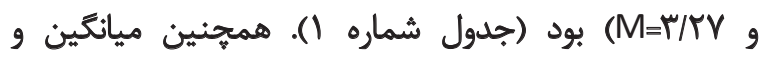

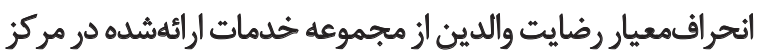

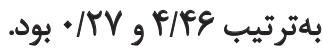

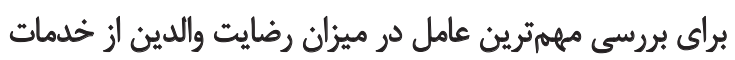

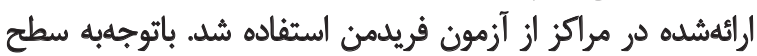

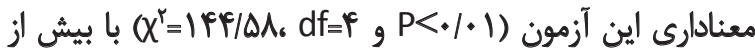

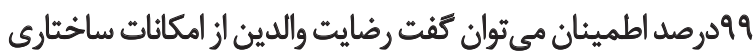

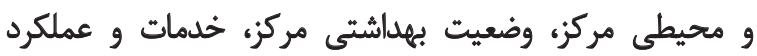

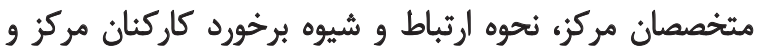

شد. درنهايت يرسشنامه محقق ساخته براي سنجش ميزان

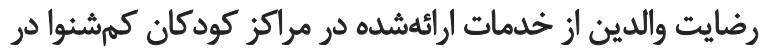

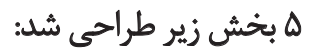

1. رضايت از امكائات ساختارى محيطى مركز (شامل V سؤال)؛ r. رضايت از شرايط بهداشتى مركز (شامل • ا سؤال)؛ ب. رضايت از خدمات و عملكرد مركز (شامل ل/ سؤال)؛

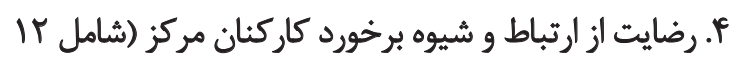

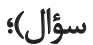
هـ. رضايت از هزينهها (شامل ب سؤال).

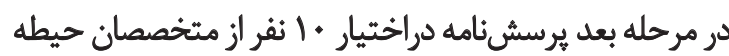

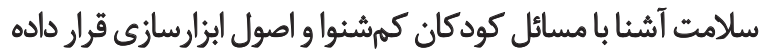

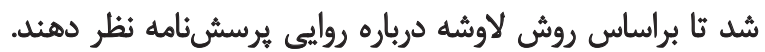

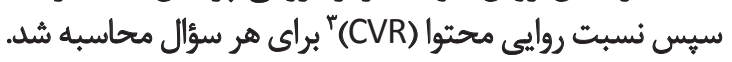

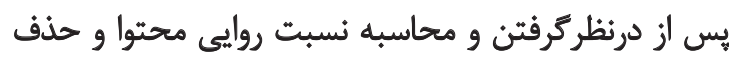

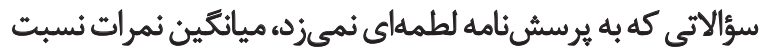

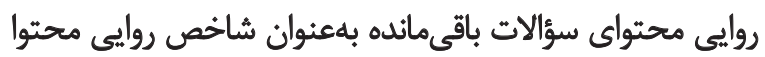

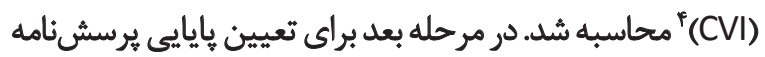

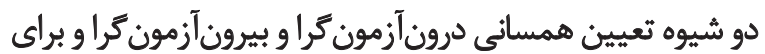

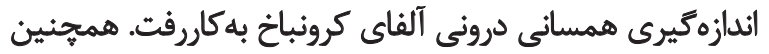

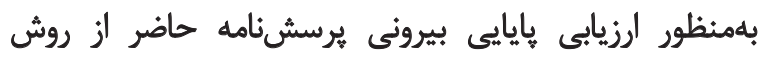

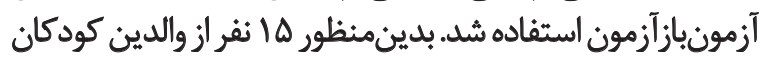

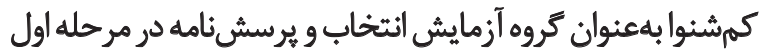

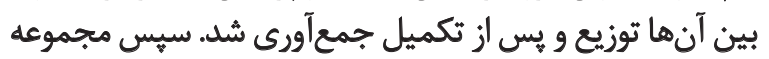

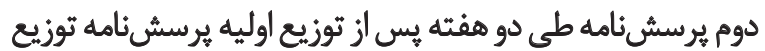

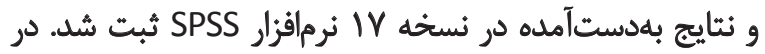

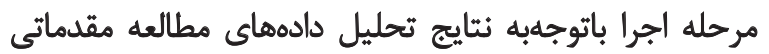

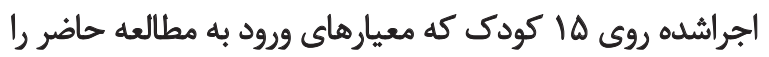

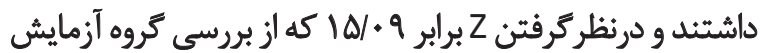

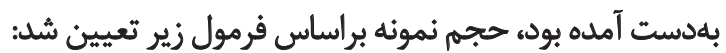

$$
n=\frac{z^{2} P(1-P)}{d^{2}}
$$

يرسشنامه تهيهشده روى والدين •9 كودى كمشنوا زير 9

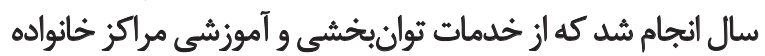

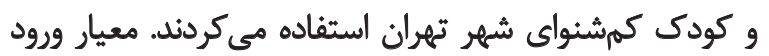

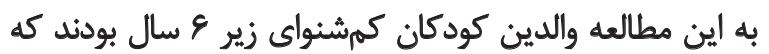

3. Content Validity Ratio (CVR)

4. Content Validity Index (CVI) 
جدول أ. آمارههاي توصيفي متغيرهاي ثيروهش.

\begin{tabular}{|c|c|c|c|c|c|}
\hline ي بيشترين مقدلر & كمترين مقدار & افحرافمعيار & مياكَين & تعداد اقراد & نوع رضايت والدين \\
\hline$ه$ & $Y M$ & .10. & $P / M$ & s. & امكانات ساختثارى و محيطى مركز \\
\hline$\Delta$ & $r / r$. &.$/ 29$ & P/PV & q. & وضعيت بهيداشتى مركز \\
\hline$P / A q$ & $r / M$ & $\pi \varphi$ & $P / \Delta F$ & \&. & هُمات و عملكرد متّخصصان مركز \\
\hline$\Delta$ & r/Ar & $\cdot M$ & $P / M$ & s. & نحوه ارتباط و شيوه برخورد كاركنان مركز \\
\hline$F / M$ & V/ev & IET & $T / T V$ & s. & هزينههاي برداختى در مقابل خدمات مركز \\
\hline F/ar & $r / M^{F}$ & $\cdot / T$ & F/Re & q. & مجموعه خلمات ارائششله در مركز \\
\hline
\end{tabular}

جدول r. همبستكى بين هريك از متغيرها و ميزان رضايت كلى.

\begin{tabular}{|c|c|c|c|}
\hline تعداد & سطح معنادارى & ضريب همبستكى اسييرمن & هتغيرها \\
\hline s. & 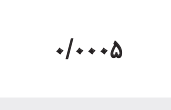 & $.18 \mathrm{P}$ & رضايت از امكانات ساختارى و محيطى مركز \\
\hline s. & $\%+\infty$ & .104 & رضيزان رضايت از وضلىيت بهداشتى مركز \\
\hline g. & $+1+\infty+\Delta$ & $\cdot|A|$ & رضايت از خلمات ارائلهنلده متخصصان مركز \\
\hline s. &.$\ldots \Delta$ & . $/ \mathrm{A}$ & رضايت از نحوه الرتباط و شيوه برخورد كاركنان مركز \\
\hline e. & .1 .4 &.$/ m$ & رضايت از هزيثههاى برداختى در مقابل خدمات مركز \\
\hline
\end{tabular}

توانبخننى

مراكز ارائه مى دهند، رابطه معنادارى وجود داشت. همجنين براى

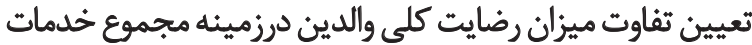

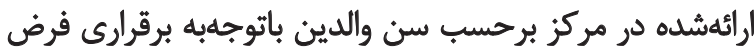

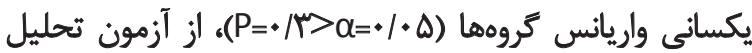

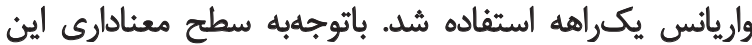

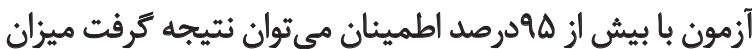

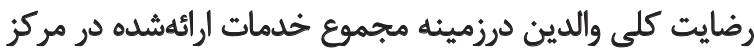

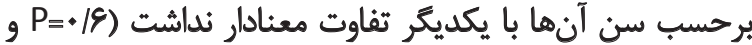

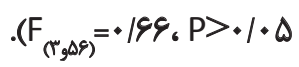

براى تعيين تفاوت ميزان رضايت كلى والدين درباره مجموع

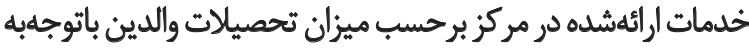

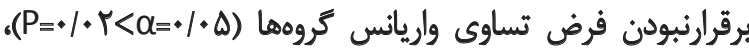

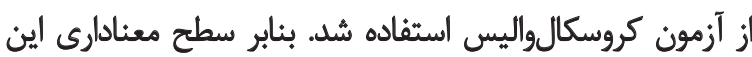

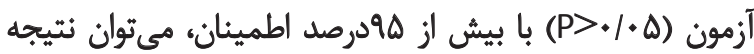

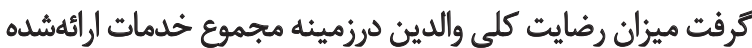
در مركز برحسب سطح تحصيلات آنها، با يكديكر تفاوت معندات منادين النار
هزينههاى يرداختى والدين درمقابل خدمات در ردههاي متفاوت قرار

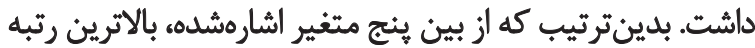

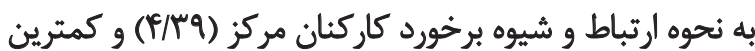

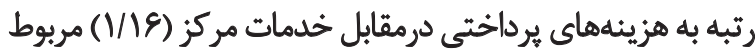

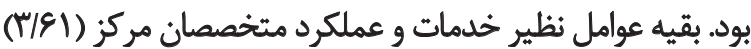

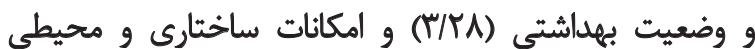

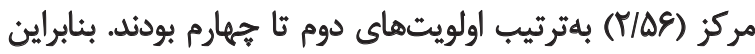

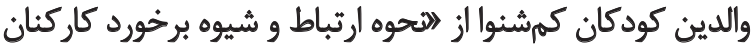

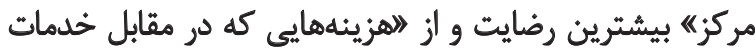
مىيرداختنده كمترين رضايت را داشتند.

در يثوهش حاضر بهمنظور بررسى ارتباط ميان هركدام از

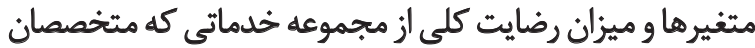

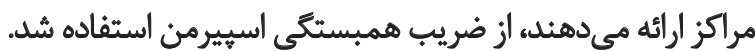

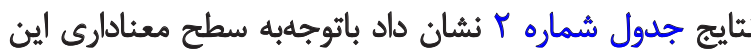

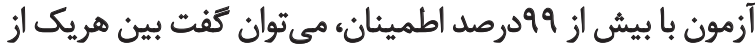

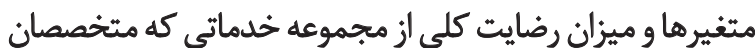




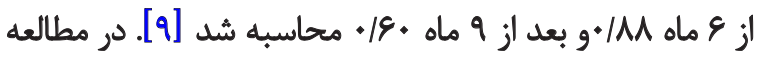

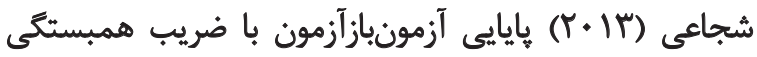

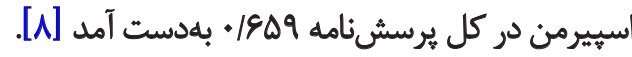

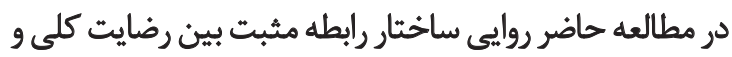

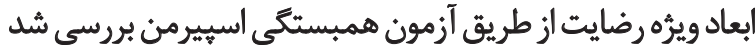

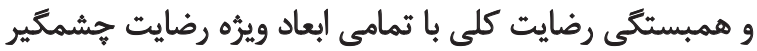

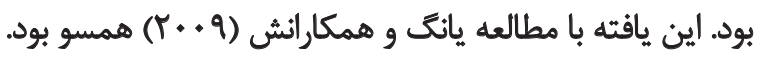

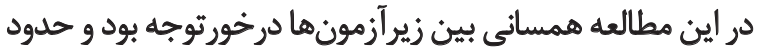

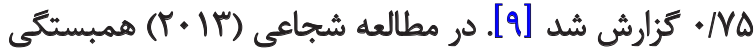

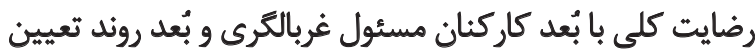

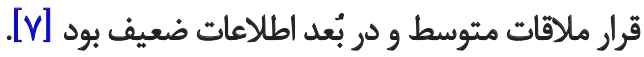

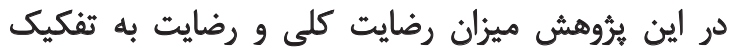

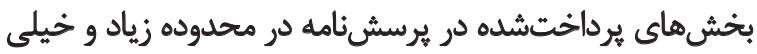

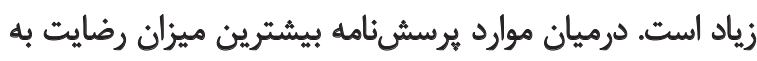

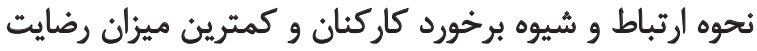

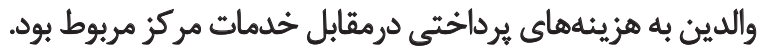

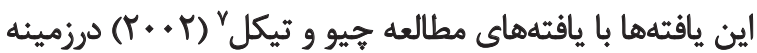

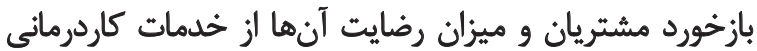

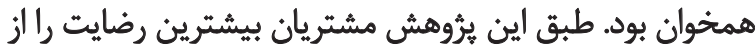

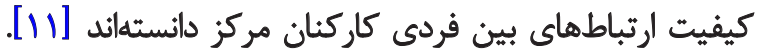

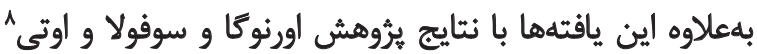

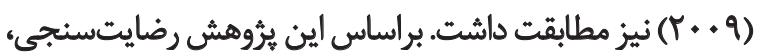

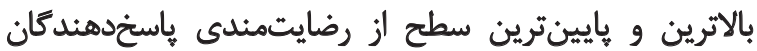

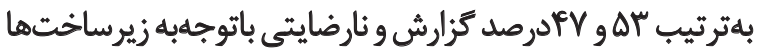

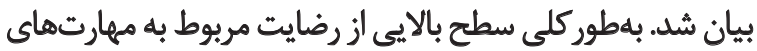

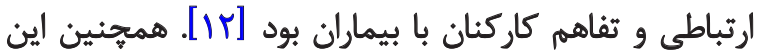

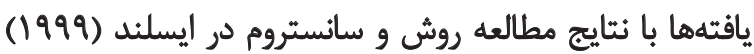

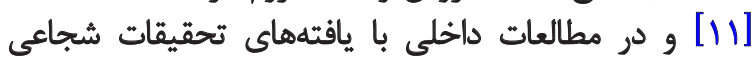

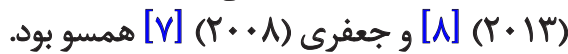
بلهعلاوه نتايج نشان مىدهد ميان رضايت كلى والدين با سن

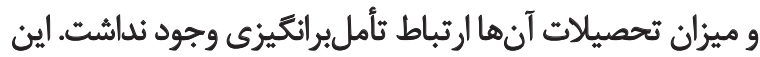

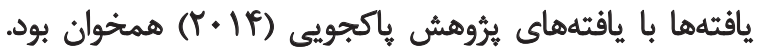

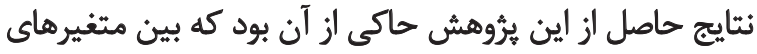

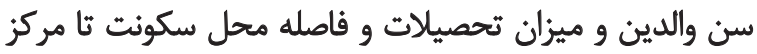

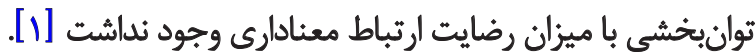

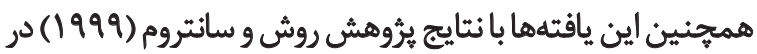

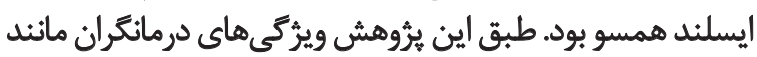

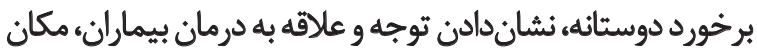

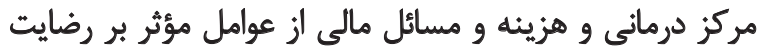
بيماران بود و تفاوت معنادارى بين رضايت مراجعان مرد مود وزئن

7. Chiu and Tikle

8. Orenuga, Sofola and Uti
نداشت (P)

در يُؤهش حاضر روايى محتوايى برسشنامه براساس روش بران

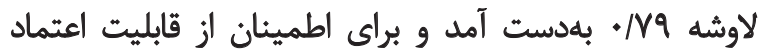

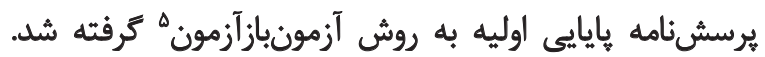

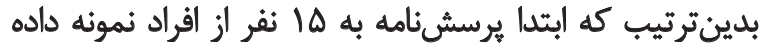

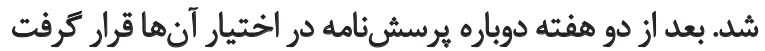

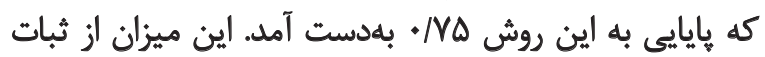

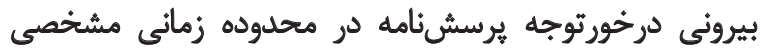

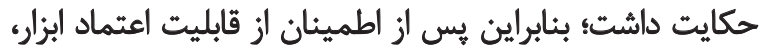

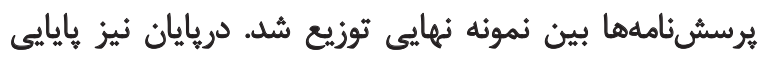

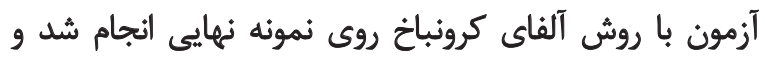

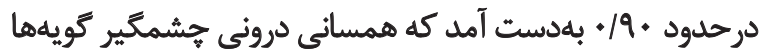

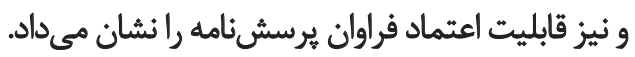

ب

نتايج حاصل از اين بثروهش حاكى از آن است يرسشنامه

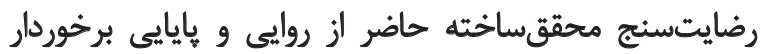

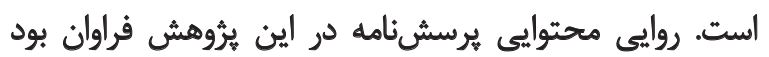
(CVI=•/N9)

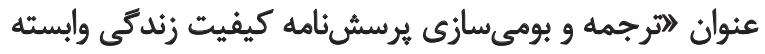

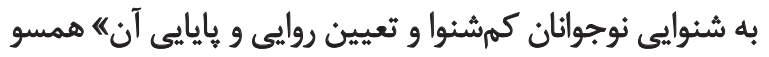

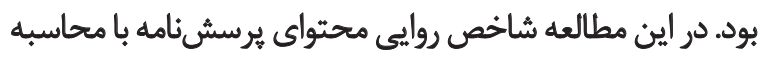

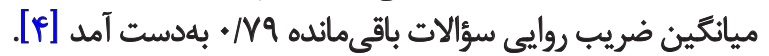

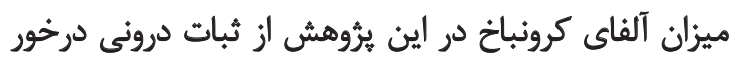

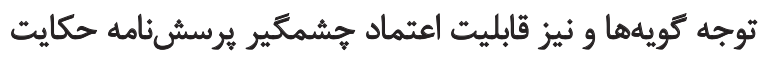

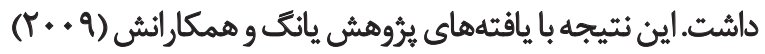

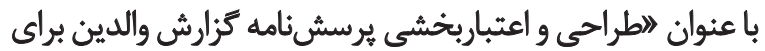

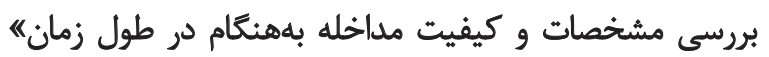

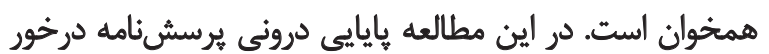

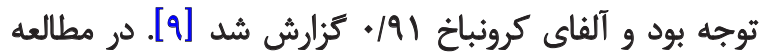

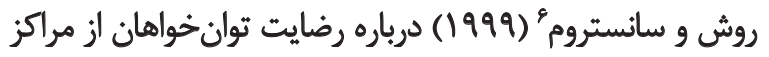

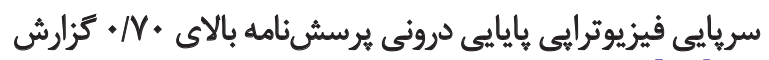

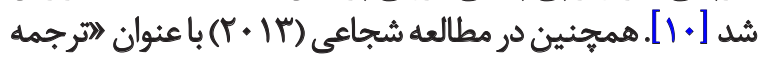

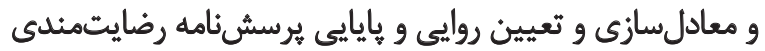

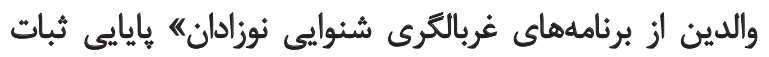

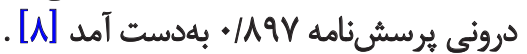

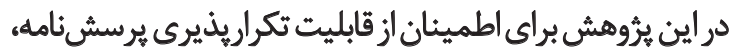

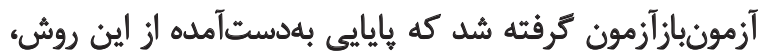

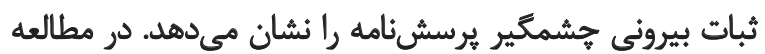

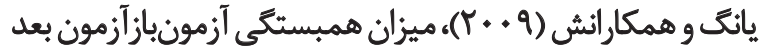

5. Test-Retest

6. Roush and Sonstroen 
References:

[1] Pakjouei SH, Vameghi R, Dejman M, Vameghi M, Kamali M. Satisfaction and related factors among the service users of private rehabilitation centers. Iranian Journal of Rehabilitation. 2014; 12(4):35-42.

[2] Karimi dermani R. [Rehabilitation of specific groups with an emphasis on social services (Persian)]. $1^{\text {st }}$ ed. Tehran:Gostardeh Pub; 2006.

[3] Bagheri-Mousavi M, Hatamizadeh N, Malayeri S. [The topic of discharge from auditory training service: the audiologists' perspective (Persian)]. Journal of Rehabilitation. 2013; 13(5):94-103

[4] Sa'adati-Boroujeni S, Hatamizadeh N, Vameghi R, Kraskian A. [Developing and validating a hearing-loss related quality of life questionnaire for adolescents (Persian)]. Journal of Rehabilitation. 2013; 13(5):84-93

[5] Fitzpatrick E, Coyle D, Durieux-Smith A, Graham I, Angus D, Gaboury I. Parents' preferences for services for children with hearing loss: a conjoint analysis study. Ear \& Hearing. 2007; 28(6):842-49. doi: 10.1097/aud.0b013e318157676d

[6] Olusanaya BO, Luxon LM, Wirz SL. Benefits and challenges of newborn hearing screening for developing countries. International Journal of Pediatric Otorhinolaryngology. 2004; 68(3):287-305. doi: 10.1016/j.ijporl.2003.10.015

[7] Hatamizadeh N, Ja'fari P, Vameghi R, Kazemnezhad A. [Client satisfaction of public and private rehabilitation day centers in Kordestan Province (Persian)]. Journal of Rehabilitation. 2008; 9(3-4):69-74.

[8] Shojaee M, Kamali M, Sameni J, CHabok A. [Parent Satisfaction Questionnaire with Neonatal Hearing Screening P, rograms: Psychometric properties of the Persian version]. International Journal of Pediatric Otorhinolaryngology. 2013; 77(11):19021907. doi: 10.1016/j.ijporl.2013.09.007

[9] Youn A, Gascon, Ramos M, Campbell M, Bamford LL. Journal of Deaf Studies and Deaf Education. 2009; 14(4):422-35. doi:10.1093/deafed/enp016.Epu 2009 jul 17 .

[10] Roush S, Sonstroen R. Development of physical therapy outpatient satisfaction survey. Physical Therapy. 1999; 79(2):159-169.

[11] Chiu T, Tikle L . Learning From Evidenece : service outcomes and client satisfaction with occupational therapy Home Based Services. American Journal of Occupational Therapy .2002; 56(2): 217-20. doi: 10.5014/ajot.56.2.217

[12] Orenuga OO, Sofola OO, Uti OO. Patient satisfaction: a survey of dental outpatients at the Lagos University Teaching Hospital, Nigeria. Nigerian Quarterly Journal of Hospital Medicine. 2009; 19(1):47-52. doi: 10.1093/deaf fed/enpo16

[13] Saadati Borujeni S, Hatamizadeh N, Vameghi R, Kraskian A. Hearing loss related quality of life in adolescents with hearing loss. Iranian Rehabilitation Journal. 2015; 13(1):43-38.

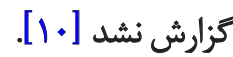

نتيجليَيرى

نتايج حاصل از اين يثروهش و انجام تحليلهاى آمارى نشان

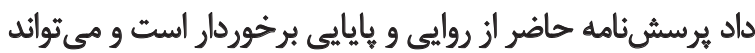

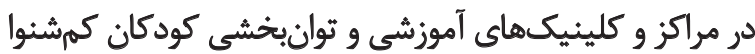

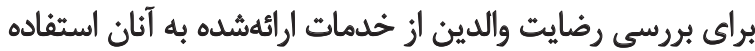

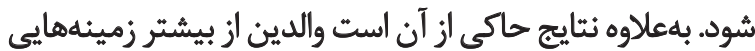

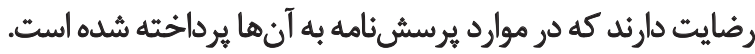

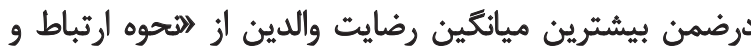

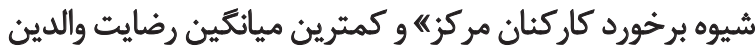

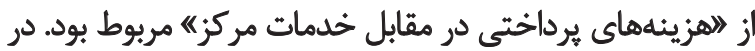

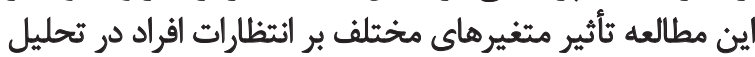

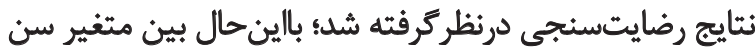

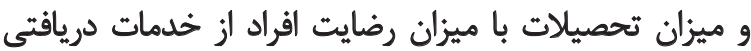

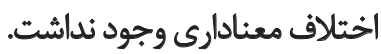

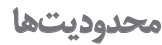

ييشتر برؤهش ها در حوزه مطالعه خود با محدوديتهايي مواجه

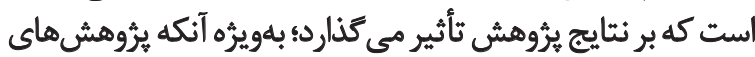

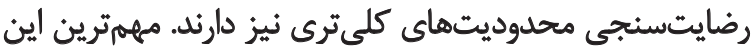

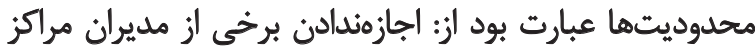

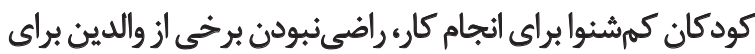

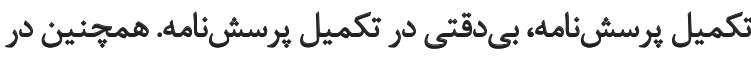

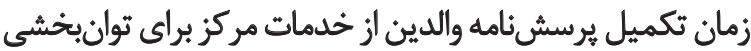

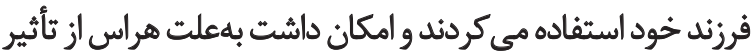

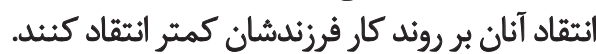

Lislintun

بهمنظور بررسى ميزان رضايت والدين از خدمات ارائهشده به

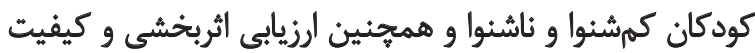

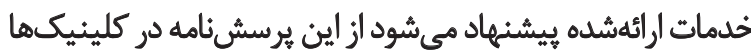

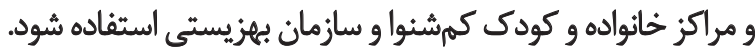

$$
\text { تشكر و قدرداني }
$$

با تشكر فراوان از مسئولان مراكز كودكان كمشنواى شهر تهران

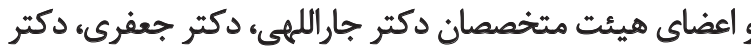

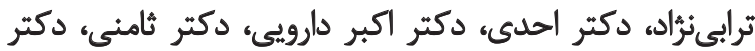

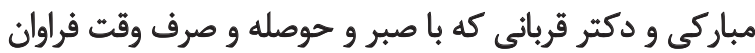

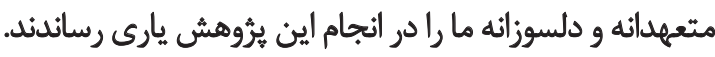


